\title{
Evaluation of immunomodulatory effect of Tinospora cordifolia leaf and stem on zidovudine induced immunotoxicity
}

\author{
G. Nageswari ${ }^{*}$, A. Harinatha Reddy ${ }^{2}$, B. Venkatappa ${ }^{3}$ \\ ${ }^{1,2,3}$ Department of Microbiology, Sri Krishnadevaraya University, Anantapur, India \\ Available online at: www.isroset.org \\ Received: 26/May/2018, Revised: 05/Jun/2018, Accepted: 21/Jun/2018, Online: 30/Jun/ 2018
}

\begin{abstract}
The present study was conducted to evaluate immunomodulatory effect of Tinospora cordifolia (T.C) leaf and stem extracts on zidovudine induced immunotoxicity. T.C leaves and stem was collected and three different extracts of stem and leaf (Aqueous, methanol, n-hexane) was prepared by Soxhlet extraction. Total 24 rats were used in the study. Rats were divided into 4 groups each of 6 rats. Group-I was treated with distilled water. Group-II rats received Zidovudine (500 mg/kg), GroupIII given alcoholic extract of T.C stem $(500 \mathrm{mg} / \mathrm{kg})+$ Zidovudine $(500 \mathrm{mg} / \mathrm{kg})$ and Group-IV received alcoholic extract of T.C leaf $(500 \mathrm{mg} / \mathrm{kg})+$ Zidovudine $(500 \mathrm{mg} / \mathrm{kg})$. Physical and hematological and immunological parameters were measured at every alternative week. At the end of study rats were sacrificed under anesthesia. Thymus and spleen was collected and weighed. These findings suggest ameliorate effect of T.C leaf and stem extract on zidovudine induced immunotoxicity.
\end{abstract}

Keywords: Zidovudine, alcoholic extract, immunomodulatory, immunotoxicity, haematological and histopathological

\section{INTRODUCTION}

Ayurveda is one of the traditional system of medicine practiced in India can be traced back to 6000 B.C. Great emphasis has been placed on research of herbal formulations which can be helpful in the management of immune, cancer and infection related disorders [1]. One of the main approaches in Ayurvedic medicine is to "increase the body's natural resistance to disease causing agents rather than directly neutralizing the agent itself [2].

Zidovudine (ZDV), also known as Azidothymidine (AZT), is an anti-retroviral medication used to prevent and treat HIV/AIDS. AZT is pro drug it has to activate by phosphorylation in lymphocytes. It is commonly given by oral route. AZT produces serious adverse effects like immunotoxicity, lactic acidosis, liver toxicity, myopathy, severe anemia, neutropenia [3].

AZT is anti-HIV drug, approved to treat HIV in the early days. It works by inhibiting an enzyme called reverse transcriptase. AZT was eventually shown to be extremely toxic and long term use causes immunosuppression. Recent discovery's suggested that some of the medicinal plants that delivers similar effects without causing side effects.

Recent years medicinal plants gain the approach in the use of various diseases. Use of medicinal plants has lesser side effects. Plant extracts used in traditional therapy are being reviewed for their chemo protective and immunomodulatory activities. According to Ayurveda T.C used to treat various conditions. T.C is a climbing shrub belonging to the family Menispermaceae. In Ayurveda T.C is used as "rasayana" which has powerful immunostimulant activity.

T.C is an important medicinal plant has been extensively invested for its different notable medicinal properties like anti-diabetic, antioxidant, immunomodulatory and antineoplastic antifungal and anti-inflammatory activities. Considering these facts the present study designed to evaluate the immunomodulatory activity of various extracts of stem and leaf of T.C in in animal model.

\section{MATERIALS AND METHODS}

\section{Collection of T.C leaves and stem}

T.C leaves and stem was collected from local area of kothacheruvu, Anantapur, Andhra Pradesh. The plant material was authenticated by botanist. Leaves and stem was dried under sunlight and made into fine powder by mechanical grinder. The powder was used for extraction.

\section{Preparation of different types of T.C stem and leaf} extracts

Three different extracts of stem and leaf (Aqueous, methanol, n-hexane) was prepared by Soxhlet extraction. The extracts was dried on water bath till solvent evaporated. The dark brown color extract was stored and used for further study [4].

\section{Animals}


Albino rats (Wistar strain) of male weighing 150$200 \mathrm{~g}$ were obtained from authorized Central animal house (Sri Raghavendra Enterprises, Bangalore, Karnataka). The animals were housed in cages under controlled conditions of temperature $\left(25^{\circ} \mathrm{C}\right)$ and alternating $12: 12 \mathrm{hr}$ cycle of light and darkness. The animals have free access to standard rat pellet diet and tap water ad libitum. The Institutional animal ethics committee (878/ac/05/CPCSEA/012/2013) has approved the experimental protocol at Post Graduate Department of Pharmacology, RIPER, Anantapur, and Andhra Pradesh [5].

\section{Study groups}

Table 1: Evaluation of immunomodulatory study of alcoholic extract of $T . C$ stem and leaf in zidovudine induce immunotoxicity.

\begin{tabular}{|l|l|c|}
\hline \multicolumn{1}{|c|}{ Groups } & \multicolumn{1}{|c|}{ Drug/Dose } & $\begin{array}{c}\text { Number of } \\
\text { animals }\end{array}$ \\
\hline Group-I & Control $(10 \mathrm{ml}$ Distilled water $/ \mathrm{kg})$ & 6 \\
\hline Group-II & Zidovudine $(500 \mathrm{mg} / \mathrm{kg})$ & 6 \\
\hline Group-III & $\begin{array}{l}\text { Alcoholic extract of } T . C \text { stem }(500 \mathrm{mg} / \mathrm{kg})+ \\
\text { Zidovudine }(500 \mathrm{mg} / \mathrm{kg})\end{array}$ & 6 \\
\hline Group-IV & $\begin{array}{l}\text { Alcoholic extract of } T . C \text { leaf }(500 \mathrm{mg} / \mathrm{kg})+ \\
\text { Zidovudine }(500 \mathrm{mg} / \mathrm{kg})\end{array}$ & 6 \\
\hline
\end{tabular}

\section{Procedure}

Total 24 rats were used in this study. Rats were divided into 4 groups each of 6 rats. Group-I was treated with distilled water. Group-II rats received Zidovudine $(500 \mathrm{mg} / \mathrm{kg}$ ), Group-III given alcoholic extract of T.C stem $(500 \mathrm{mg} / \mathrm{kg})+$ Zidovudine $(500 \mathrm{mg} / \mathrm{kg}$ ) and Group-IV received alcoholic extract of $T . C$ leaf $(500 \mathrm{mg} / \mathrm{kg})+$ Zidovudine $(500 \mathrm{mg} / \mathrm{kg})$. All the rats received receptive drugs for 8 weeks. Physical and haematological parameters were measured every alternative week $\left(2^{\text {nd }}, 4^{\text {th }}, 6^{\text {th }}\right.$ and $8^{\text {th }}$ week). Immunological parameters were measured on $8^{\text {th }}$ week. At the end of study period $\left(8^{\text {th }}\right.$ week) rats were sacrificed under anesthesia (Halothane). Thymus and spleen was collected and weighed. The specimens were stored in $10 \%$ formalin and used for histopathological examination.

\section{Observations}

Physical parameters

Physical parameters were measured on alternative weeks $\left(2^{\text {nd }}\right.$, $4^{\text {th }}, 6^{\text {th }}$ and $\left.8^{\text {th }}\right)$ during the study period.

\section{Body weight (gm)}

Rat's body weight was recorded by using digital electronic balance. The weight was expressed in mean gm.

\section{Food intake (gm)}

Total food intake of each animal was estimated by below formula method

Food intake (gm) $=$ "The weight of food kept in the cage The food remaining in the cage after $24 \mathrm{~h}$ ".

The food intake was expressed in mean gm.

Thymus weight (gm)

The isolated thymus weight was measured by using electronic weighing machine. Spleen weight was expressed in gm.

\section{Spleen weight (gm)}

The isolated spleen weight was measured by using electronic weighing machine. Thymus weight was expressed in gm.

\section{Immunomodulatory parameters}

\section{Estimation of humoral antibody response to SRBC} (Hemagglutination antibody titer test) $(\%)$

Fresh blood was collected from healthy sheep at and mixed with sterile Elsever's solution (1:1). The blood was then centrifuged at $1609.92 \times g$ for $5 \mathrm{~min}$ to enable red blood cells to settle at the bottom of the test tube. The supernatant was discarded, leaving sheep red blood cells (SRBC) pellets that were washed three times with pyrogen-free phosphate buffered saline ( $\mathrm{pH}$ 7.2). They were then kept under refrigeration for use in the immunization and challenge study. Rats were immunized by injecting $0.5 \mathrm{ml}$ of SRBCs i.p end of the $8^{\text {th }}$ week. Blood samples were collected by cardiac puncture. Blood was centrifuged at $1609.92 \times g$ to get serum. Antibody titers were then determined by the hemagglutination technique as described by Gaur et al. 2009). Serial two-fold dilutions of serum were made with normal saline in microtiter plates of 96-well capacity and SRBC $(25 \mu \mathrm{L}$ of $1 \%$ SRBC prepared in normal saline) added to each of these dilutions. The hemagglutination plates were then incubated at $37^{\circ} \mathrm{C}$ for $1 \mathrm{~h}$ and then examined for hemagglutination. The reciprocal of the highest dilution of the test serum giving agglutination was taken as the hemagglutination antibody titer in percentage $(\%)$.

\section{Estimation of delayed type hypersensitivity response (\%)}

Rat paw model used to determine the delayed type of hypersensitivity response. At the end of $8^{\text {th }}$ week rats was primed by subcutaneous injection $(0.1 \mathrm{ml})$ with suspension containing $1 \times 10^{8}$ SRBC into right hind footpad. The contralateral paw also received an equal volume of $0.1 \%$ phosphate buffered saline (PBS). The extent of delayed-type hypersensitivity (DTH) response in the rats was determined by measuring the footpad thickness after $0,4,8$ and $24 \mathrm{~h}$ of challenge using plethysmometer. The difference in the thickness of the right hind paw and the left hind paw was then used as a measure of DTH reaction and was expressed as a mean percent increment in edema. It was calculated by using the below formula:

$$
\% \text { increment in edem }=\frac{\text { Lefe foot pad challenged with antigen }- \text { Right foot pad control }}{\text { Left foot pad challenged with antigen } \times 100}
$$

\section{Estimation of bleeding time ( $\mathrm{min}$ )}

Bleeding was estimated by standard Duke's method. It was measured in different time periods $(2,4,6$ and 8$)$ weeks. In the procedure rat paws was sterilized with spirit and allowed to dry. Sterilized needle was taken and pricked at sterilized paw. Pricking time was noted. Stain was taken with filter paper after $30 \mathrm{sec}$. It was repeated every $20 \mathrm{sec}$ till the bleeding stop. The time of no stain was considered as bleeding time and it was expressed in mean minutes. 


\section{RESULTS AND DISCUSSION}

Effect of T.C leaf and stem on physical parameters Body weight, food intake, thymus and spleen weight were taken as a physical parameters. Body weight and food intake was measured on different time periods and compared. They were measured on $2^{\text {nd }}, 4^{\text {th }}, 6^{\text {th }}$ and $8^{\text {th }}$ week. Control group showed increase in weight and food intake compared to standard and test groups as week's progress. Group-II showed increase in the body weight and food intake compared to other groups. Increase in the Group-II lesser than Group-I, III and IV. On $8^{\text {th }}$ day group-II showed significant $(\mathrm{p}<0.04)$ difference compared to other groups. Group-III and IV not showed any significant difference. Within the groups also similar results were observed.

Group-II showed significant $(\mathrm{p}<0.001)$ decrease in thymus and spleen weight compared to Group-I. Co-administration of plants extracts significantly prevented the AZT induced changes in thymus and spleen. Group-III and IV showed significant $(\mathrm{p}<0.001)$ difference compared to Group-II. Group-I compared to Group-III and IV not showed any significant difference. AZT induced changes in spleen and thymus was reduced by co-administration of T.C leaf and stem.

In this study rats treated with AZT showed decrease in the body weight compared to control. The $20-30 \%$ decrease was observed between the weeks. This decrease was reversed with the treatment of T.C leaf and stem. Naiho et al., 2014 [6] observed that AZT treatment reduced the body weight up to $40 \%$. The present study results also showed similar effect. Lamperth et al., 1991[7] observed that AZT-treated animals lost $10 \%$ of their original weight by the end of the third month of the experiment. It may be due to decrease the food intake can reduce the body weight. AZT has effect on food intake. In this study results showed decrease food intake up to $10-20 \%$. As weeks increases loss of body weight is associated with decrease in food intake. AZT may have action on central nervous system and GIT. T.C treated rats showed decrease in food intake and body weight but not like AZT treated rats.

T.C stem and leaf treated rats showed lesser effect than AZT treated rats. Test drug treatment reduces the AZT effect but cannot reach the control group. This result indicates T.C stem and leaf can prevent the AZT effect but cannot bring to normal level. If it has reach to normal level may require long term therapy. Plant extract contains the various phytochemicals. They have various actions. In the test drug may have the pytochemicals which are responsible for the prevention of AZT induced changes in body weight and food intake. It is well understood decrease the food intake leads to decrease the body weight. In the present study also similar effect was observed. AZT reduces the food intake leads to decrease the body weight.
Kenneth et al., 1996 [8] observed that AZT administration reduce the food intake up to $40 \%$. In the present study also similar effect was observed. He explains that AZT treatment can change the GIT epithelial function and hunger center. Inhibition of hunger center can reduce the food intake. It indicate AZT act on hunger center and reduce the food intake. This effect of AZT is inhibited by T.C leaf and stem because rats showed increase in the food intake. T.C stem and leaf significantly prevented the AZT induced changes in body weight and food intake.

Table 2: Effect of Tinospora cordifolia leaf and stem extract on body weight in Zidovudine treated rats

\begin{tabular}{|l|c|c|c|c|}
\hline \multirow{2}{*}{ Groups } & \multicolumn{4}{|c|}{ Body weight $(\mathbf{g m})(\mathbf{M E A N} \pm$ SD) } \\
\cline { 2 - 5 } & $\mathbf{2}^{\text {nd }}$ week & $\mathbf{4}^{\text {th }}$ week & $\mathbf{6}^{\text {th }}$ week & $\mathbf{8}^{\text {th }}$ week \\
\hline Group-I & $190.45 \pm 1.98$ & $215.12 \pm 1.56$ & $260.89 \pm 1.78$ & $274.91 \pm 1.56^{*}$ \\
\hline Group-II & $192.34 \pm 1.90$ & $205.10 \pm 1.56$ & $245.34 \pm 1.56$ & $245.04 \pm 1.45$ \\
\hline Group-III & $194.13 \pm 2.01$ & $220.13 \pm 1.45$ & $260.90 \pm 1.43$ & $285.45 \pm 1.23^{*}$ \\
\hline Group-IV & $193.89 \pm 1.78$ & $232.23 \pm 2.01$ & $255.90 \pm 1.01$ & $280.45 \pm 1.90^{*}$ \\
\hline
\end{tabular}

(*p<0.05 significant compared Group-II with other groups)

Graph-1: Effect of Tinospora cordifolia leaf and stem extract on body weight in zidovudine treated rats

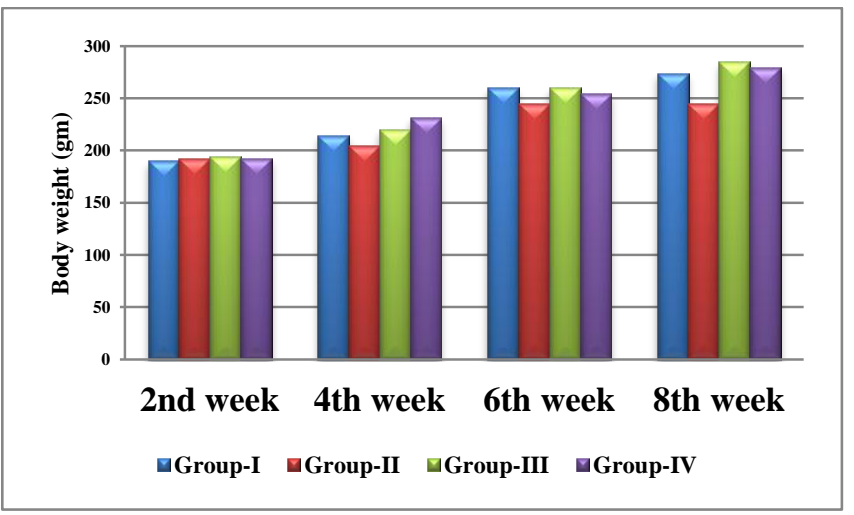

Table 3: Effect of Tinospora cordifolia leaf and stem extract on food intake in zidovudine treated rats.

\begin{tabular}{|l|c|c|c|c|}
\hline \multirow{2}{*}{ Groups } & \multicolumn{4}{|c|}{ Food intake (gm) (MEAN \pm SD) } \\
\cline { 2 - 5 } & $\mathbf{2}^{\text {nd }}$ week & $\mathbf{4}^{\text {th }}$ week & $\mathbf{6}^{\text {th }}$ week & $\mathbf{8}^{\text {th }}$ week \\
\hline Group-I & $20.78 \pm 1.89$ & $20.12 \pm 1.90$ & $21.12 \pm 1.12$ & $25.89 \pm 2.45$ \\
\hline Group-II & $19.90 \pm 1.34$ & $21.90 \pm 2.90$ & $20.90 \pm 0.34$ & $22.23 \pm 0.12$ \\
\hline Group-III & $18.90 \pm 2.89$ & $22.12 \pm 1.23$ & $26.12 \pm 1.23$ & $24.12 \pm 0.93$ \\
\hline Group-IV & $21.12 \pm 1.90$ & $26.16 \pm 1.34$ & $28.92 \pm 2.92$ & $27.89 \pm 1.78$ \\
\hline
\end{tabular}

Graph 2: Effect of Tinospora cordifolia leaf and stem extract on food intake in zidovudine treated rats. 


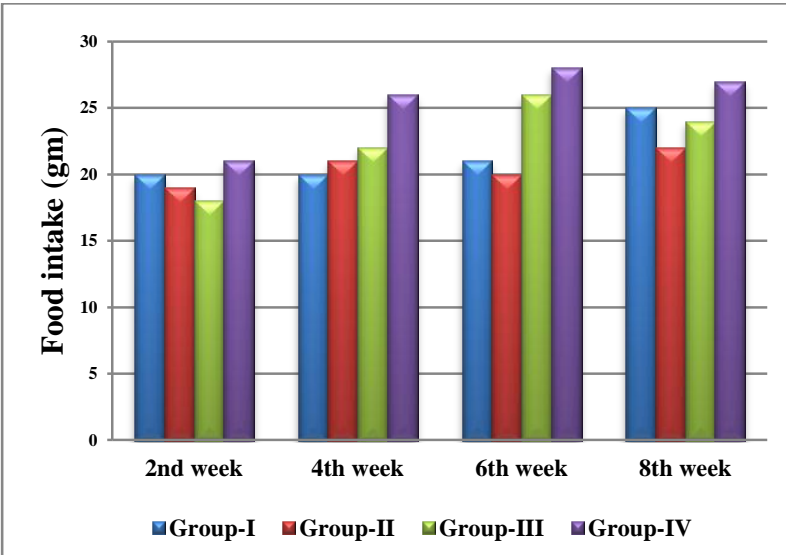

AZT treatment decreased the spleen and thymus weight compared to control group. T.C stem and leaf prevented the AZT induced changes in the thymus and spleen. These two organs are plays major role in the immune system. Thymus plays major role in the synthesis of $\mathrm{T}$ and $\mathrm{B}$ cells. Spleen plays major role in the development of immune cells. Changes in the thymus and spleen can affect the immune function of the body. Rats treated with AZT causes changes in the spleen and thymus structure. These reduce the $\mathrm{T}$ and $\mathrm{B}$ cell levels. This one of the reason AZT treatment reduces the immune power of the body. Chow et al., 1998 [9] studied effect of AZT on the spleen and thymus. In his study it was observed that rats treated with AZT showed decrease in the thymus and spleen weight. In the present study also similar results were observed.

AZT for 3 months to the rats observed that decrease in the spleen and thymus weight. The author explains this effect by AZT pharmacokinetic property. They were observed that AZT concentrates in the spleen and thymus after administration. This leads to accumulation of AZT in the tissues. High concentration of AZT at local area can cause the adverse effects. They were observed that rats treated with AZT increases the apoptosis in the thymus and spleen cells. Increase the apoptosis reduce the cell number leads to decrease in the organ weight. T.C leaf and stem treatment prevented the AZT induced changes in spleen and thymus. This effect may be due to inhibition of apoptosis of the thymus and spleen cells. When plant extract inhibit the apoptosis leads to decrease the cell destruction. Bioactive compounds present the T.C stem and leaf are responsible for this effect.

Table 4: Effect of Tinospora cordifolia leaf and stem extract on thymus weight in zidovudine treated rats.

\begin{tabular}{|l|c|}
\hline \multicolumn{1}{|c|}{ Groups } & Thymus weight $(\mathbf{g m})(\mathbf{M E A N} \pm$ SD) \\
\hline Group-I & $0.26 \pm 1.34$ \\
\hline Group-II & $0.15 \pm 1.12^{*}$ \\
\hline Group-III & $0.27 \pm 1.23^{*, \#}$ \\
\hline Group-IV & $0.26 \pm 1.45^{*, \#}$ \\
\hline
\end{tabular}

(* $\mathbf{p}<0.05$ significant compared Group-I with other groups, \#p $\mathbf{p} 0.05$ significant compared Group-II with other groups)

Table 5: Effect of Tinospora cordifolia leaf and stem extract on spleen weight in zidovudine treated rats.

\begin{tabular}{|c|c|}
\hline Groups & Spleen weight $(\mathbf{g m})(\mathbf{M E A N} \pm$ SD) \\
\hline Group-I & $0.97 \pm 1.23$ \\
\hline Group-II & $0.73 \pm 1.46^{*}$ \\
\hline Group-III & $1.27 \pm 2.78^{*, \#}$ \\
\hline Group-IV & $1.36 \pm 1.29^{*, \#}$ \\
\hline
\end{tabular}

(*p<0.05 significant compared Group-I with other groups, \#p<0.05 significant compared Group-II with other groups)

In SRBC change test Group-II showed significant $(\mathrm{p}<0.001)$ decrease in the $A B$ titer values compared to control group. Rats treated with the plant extract significantly prevent the zidovudine induced changes in SRBC challenge. The difference was statically significant. The control and test groups showed similar results. T.C leaf and stem extract showed positive for steroids. The phytochemcal may act as immunomodulater. Due its effect reduced the $\mathrm{AB}$ titer value.

The National Toxicity Program conducted a study on AZT induced immunotoxicity. In the program animals were administered AZT for 180 days. On the last day they were subjected to SRBC challenge on $A B$ titer. The study results showed that AZT treatment decrease the titer level compared to control group. In this study also rats treated with AZT showed decrease in titer value of $8^{\text {th }}$ week. The decrease the titer value may be due the effect of AZT on immune system. Decrease the immune cell function can reduce the titer value. Rats treated with T.C stem and leaf prevented the AZT induced changes in the SRBC challenge on $\mathrm{AB}$ titer. Test drug may contain the chemicals to increase the immune cell function. Increase in immune cell count and function can lead to increase in the titer value.

The effect of T.C on SRBC challenge on AB titer value. The study results showed increase the titer value compared to inducing drug group. T.C administration increased the titer value. In the present study also co-administration of T.C leaf and stem increase the titer value compared to AZT group. This effect may due to stimulation on immune system.

Table 6: Effect of Tinospora cordifolia leaf and stem extract on SRBC challenge on AB titer values in zidovudine treated rats.

\begin{tabular}{|c|c|}
\hline Groups & SRBC challenge on AB titer (MEAN \pm SD) \\
\hline Group-I & $96.45 \pm 1.90$ \\
\hline Group-II & $35.90 \pm 2.45^{*}$ \\
\hline Group-III & $93.19 \pm 1.34^{*, \#}$ \\
\hline Group-IV & $93.12 \pm 1.90^{*, \#}$ \\
\hline
\end{tabular}

$(* \mathrm{p}<0.05$ significant compared Group-I with other groups, \#p<0.05 significant compared Group-II with other groups, 
$\$ p<0.05$ significant compared Group-III with other groups).

Graph-3: Effect of Tinospora cordifolia leaf and stem extract on SRBC challenge on AB titer values in zidovudine treated rats.

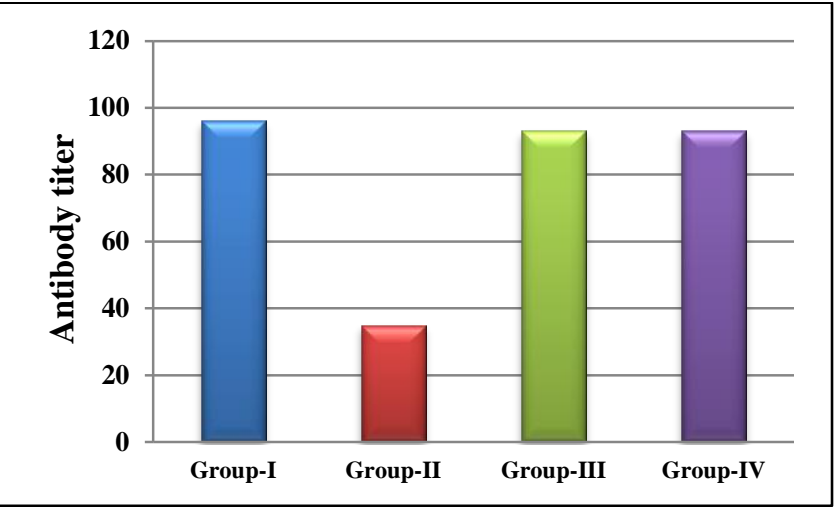

Group-II showed significant increase in paw volume compared to Group-I. Co-administration of T.C leaf and stem significant inhibited the increase in the paw volumes. T.C leaf and stem have anti-inflammatory and immunomodulatory effect. Those actions are useful to reduce the paw volumes. The differences between the groups is statically significant $(\mathrm{p}<0.001)$.

Table 7: Effect of Tinospora cordifolia leaf and stem extract on rat paw volume in zidovudine treated rats

\begin{tabular}{|l|c|c|c|c|}
\hline \multirow{2}{*}{ Groups } & \multicolumn{4}{|c|}{ Rat paws volumes (\%) (MEAN $\mathbf{( M D})$} \\
\cline { 2 - 5 } & $\mathbf{0 ~ h r}$ & $\mathbf{4}^{\text {th }} \mathbf{h r}$ & $\mathbf{8}^{\text {th }} \mathbf{h r}$ & $\mathbf{2 4}^{\text {th }} \mathbf{h r}$ \\
\hline Group-I & $10.12 \pm 0.45$ & $23.90 \pm 1.56$ & $45.89 \pm 2.34$ & $56.23 \pm 0.23$ \\
\hline Group-II & $12.05 \pm 0.56$ & $34.89 \pm 2.90^{*}$ & $56.32 \pm 1.89^{*}$ & $65.67 \pm 1.34^{*}$ \\
\hline Group-III & $10.34 \pm 1.45$ & $20.12 \pm 0.90^{*, \#}$ & $42.78 \pm 2.56^{*, \#}$ & $50.56 \pm 0.12^{*, \#}$ \\
\hline Group-IV & $10.95 \pm 0.23$ & $19.45 \pm 0.43^{*, \#}$ & $40.45 \pm 1.34^{*, \#}$ & $48.45 \pm 0.53^{*, \#}$ \\
\hline
\end{tabular}

(*p<0.05 significant compared Group-I with other groups, \#p<0.05 significant compared Group-II with other groups)

Prostaglandins are involves in the pathology of various diseases. Mainly they will cause the inflammation, tissue necrosis, muscle contraction and other abnormalities. Rats administered AZT showed decrease in the PGE2 levels compared to control group. It was statically significant $(\mathrm{p}<0.05)$. T.C leaf and stem administration prevented the AZT induced changes. Group-III and IV also showed significant difference compared with Group-I.

AZT induces the immune reactions. It was observed in the various studies. AZT treatment increase the rat paw volumes as time increases. Rats treated with T.C stem and leaf prevented the AZT induced increase in the paw volumes. Administration of irritant in rat paw can stimulate the immune reactions and increase the accumulation and aggregation of immune cells and mediators. These immune cells release the inflammatory mediator's leads to increase in the paw volume.
Lakshmi et.al., 2016 [10] studied the anti-inflammatory effect of T.C. They were observed that decrease the paw volumes. Similar results were observed in this study. This effect may be due to plant extract showed positive for steroids test. Steroids commonly known as anti-inflammatory drugs, this effect may be useful in the rat paw model.

\section{CONCLUSION}

From the above results, it can be concluded that T.C has potential immunomodulatory activity. This study provides scientific understanding to further determine the immunomodulatory activity values and investigate other pharmacological properties of T.C.

\section{ACKNOWLEDGEMENT}

We are grateful to The University Grants Commission (UGC) for funding this study under Basic Scientific Research (BSR). The authors express their sincere thanks to all the authors in reference list for support to this research.

\section{REFERENCES}

[1]. P.S. Byadgi, "Vyadhiksamatwa. Parameswarappa's Ayurvediya Vikriti Vigyan \& Roga Vigyan, 1st edition, Volume 1. Varanasi, Chaukhambha Sanskrit Sansthan", 292-305, (2007).

[2]. S. Preetam, K.D.H. Lohith, D. Chanda, S.P. Shubham, C. Ruplal, “ Traditional and ayurvedic foods of Indian origin”, Journal of Ethnic Foods, 2(3), 97-109, 2015.

[3]. E. Frederick, M.D. Harlass, "The pharmacology of zidovudine", Primary care update, 3(2), 58-62, 1996.

[4]. S. Mahuya, D.S. Gauri, C. Biswajit, 2011, "Effects of aqueous extract of Tinospora cordifolia on functions of peritoneal macrophages isolated from $\mathrm{CCl} 4$ intoxicated male albino mice", BMC Complementary and Alternative Medicine, 11, 102-106, 2011.

[5]. R.S. Gupta, A. Sharma, "Anti-fertility effect of Tinospora cordifolia stems extract in male rats", Indian Journal of Experimental Biology, 41(8), 885-889, 2003.

[6]. A.O. Naiho, K.M. Nwaokolo, M.O. Odigie, " Zidovudine therapy: Effects on histology of kidney of Wistar rats" Israel Journal of Health Policy Research, 3(4), 60-67, 2014.

[7]. L. Lamperth, M.C. Dalakas, F. Dagani, J. Anderson, R. Ferrari, "Abnormal skeletal and cardic muscle mitochondria induced by zidovudine (AZT) in human muscle In vitro in an animal model", Laboratory Investigation, 65(6), 742-751, 1991.

[8]. M.A. Kenneth, E. Walter E .Tucker, H. Gerald, D.M. Paulo, “ Nonclinical toxicology studies with zidovudine: Acute, sub acute and chronic toxicity in rodents, dogs and monkeys", Fundamental And Applied Toxicology, 32, 129-139, 1996.

[9]. H.H.Chow, G. Brookshier, "Tissue deposition of zidovudine and its phosphorylated metabolites in zidovudine treated healthy and retrovirus infected mice", Pharmaceutical Research, 15, 139-144, 1988.

[10]. P. Lakshmi Deepika, Jagadeesh, P. Supriya, Sowmya, "Analgesic, anti-inflammatory activity of Tinospora cordifolia and Valeriana Wallichi in Albino rats", IOSR Journal of Pharmacy and Biological Sciences, 11(2), 18-22, 2016. 